\title{
Assessment of Hemodialysis Adequacy in Patients with End Stage Renal Disease in a Military Hospital of Dhaka, Bangladesh
}

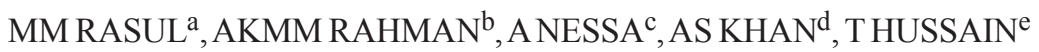

Summary:

Introduction: The burden of kidney disease patients requiring renal replacement therapy is increasing day by day. Hemodialysis (HD) constitutes the most common form of renal replacement therapy (RRT) worldwide. Determining the adequacy of hemodialysis, Urea kinetic modeling (UKM) is an important tool for this. The aim of this study was to determine hemodialysis adequacy by UKM.

Material \& Methods: A total 137 patients were sampled in dialysis center of Combined Military Hospital (CMH) Dhaka. This was a cross sectional study. Data were collected from predialysis, postdialysis and next predialysis blood sample. Mean of adequacy parameters like single pool $\mathrm{Kt} / \mathrm{V}$ $(\mathrm{spKt} / \mathrm{V})$, urea reduction ratio (URR), time average concentration of urea (TACurea) and normalized protein catabolic rate (NPCR) were calculated and compared between twice and thrice per week hemodialysis groups. Also compared adequacy variables between groups who achieved cutoff values and who did not achieve it.

Introduction:

Chronic kidney disease (CKD) is a devastating disease. The term "end- stage renal disease" (ESRD) generally refers to CKD treated with either dialysis or transplantation. Prevalence of ESRD in Bangladesh not

a. Md. Maksudur Rasul, Combined Military Hospital, Dhaka Cantonment, Dhaka, Bangladesh

b. AKM Mijanur Rahman, Combined Military Hospital, Dhaka Cantonment, Dhaka, Bangladesh

c. Azizun Nessa, Combined Military Hospital, Dhaka Cantonment, Dhaka, Bangladesh

d. Ajfar Sazid Khan, Combined Military Hospital, Dhaka Cantonment, Dhaka, Bangladesh

e. Tahmeed Hussain, Combined Military Hospital, Dhaka Cantonment, Dhaka, Bangladesh

Address of Correspondence: Md. Maksudur Rasul, Combined Military Hospital, Dhaka Cantonment, Dhaka, Bangladesh, Email: ahmed4994@gmail.com

Received: 2 Jan., 2019

Accepted: 21 August, 2019
Results: One hundred (72.99\%) patients were on 8 hours/week and 37 (27\%) were on 12 hours/week hemodialysis session. Only 21(21\%) and 16(43\%) could achieve spKt/V cut off value among 8 hour and 12 hours group respectively. Eighty (58.39\%) patients had URR $<65 \%$ in this study. Blood flow e+250 ml/ min group had significantly better dialysis adequacy than blood flow $<250 \mathrm{ml} / \mathrm{min}$ group, URR $(81.31 \pm 10.21$ vs. $54.51 \pm 11.52$ and p-value $<0.001)$, spKt/V (1.99 \pm 0.41 vs. $1.41 \pm 0.31$ pvalue $<0.001$ ) Thrice weekly hemodialysis group achieved better adequacy than twice weekly group.

Conclusion: Frequency and blood flow of dialysis are strongly associated with adequacy of hemodialysis as evidenced by spKt/V and URR value. So to achieve hemodialysis adequacy, increasing the frequency of dialysis from two to three sessions per week is recommended.

Key words: Assessment, Hemodialysis adequacy, Urea Kinetic Modeling (UKM).

(J Bangladesh Coll Phys Surg 2019; 37: 169-174) DOI: http://dx.doi.org/10.3329/jbcps.v37i4.43345

known but age-adjusted incidence rate of ESRD in India has been estimated to be 229 /million population ${ }^{1}$. Diabetes is the main cause of kidney failure in most countries, accounting for $40 \%$ or more of new patients. ${ }^{2}$ Prevalence of CKD seems to be increasing particularly in older individuals ${ }^{3}$. Hemodialysis is the mainstay therapy which is offered for ESRD patients who cannot undergo renal transplantation. Situation of Bangladesh is not different. A central issue in the management of patients undergoing maintenance hemodialysis (HD) is the assessment of the adequacy of dialysis ${ }^{4}$. Despite its dramatic success at saving lives, HD remains far from perfect therapy. More than $20 \%$ of hemodialysis patients die each year ${ }^{5}$. In developed countries usually hemodialysis is done thrice a week. However in India only $20 \%$ of patients are dialyzed 3 times a week 6 . Although it is well-known that increasing the frequency of dialysis improves the quality of life but it is a difficult 
option due to pressure from too many patients and inadequate hemodialysis machines.

UKM is a method of assessing the appropriate dose of dialysis and assessed by several indicators such as percent reduction of urea during dialysis (URR), total clearance of urea normalized for distribution volume (Kt/ $\mathrm{V})$, protein catabolic rate (PCR) and time average concentration of urea (TAC). Most of these parameters are calculated with mathematical formulas. 'Clinical signs and symptoms alone are not reliable indicators of hemodialysis adequacy' ${ }^{7}$.To ensure a sufficient dialysis, the delivered dose should be measured and monitored routinely. UKM was the best method for routine measurement of the dose of hemodialysis ${ }^{8}$. However, it is the not simple to implement. The two widely accepted measures of urea clearance are $\mathrm{Kt} / \mathrm{V}$, and URR ${ }^{9}$. Several parameters must be considered to provide adequate dialysis, such as control of fluid overload and electrolytes disturbance, correction of metabolic acidosis and dialysis dose.${ }^{10}$ National Kidney Foundation Kidney Disease Outcome Quality Initiative (NKF-KDOQI) guidelines recommend URR greater than $65 \%$ and $\mathrm{Kt} / \mathrm{V}$ greater than 1.2. HD for 12 hours/week is the standard and widely accepted regime. But 'there is a tendency to shorten dialysis time to reduce cost and to increase patients' convenience ${ }^{11}$. The present study conducted to find out the hemodialysis adequacy by UKM among the Bangladeshi patients on maintenance hemodialysis therapy. This study will enrich our knowledge and thus help in the management of patients of end stage kidney disease.

\section{Material and method:}

This was a hospital based cross sectional study conducted among the ESRD patients on maintenance hemodialysis (MHD) at dialysis center of CMH Dhaka from July 2014 to June 2015. Only adult patients (age more than 18 years) on MHD for at least three months through arterio-venous fistula (AVF) were included and those who do infrequently $(<2$ sessions /week) were excluded from the study. Purposive sampling was done among patients who fulfilled the selection criteria. After obtaining relevant clinical parameter, data collected from predialysis, postdialysis and next predialysis blood sample. Haemodialysis adequacy parameters were done among the study population only once at the entry into this study. SpKt/V, URR, TACurea and nPCR were calculated. Mean of adequacy parameters were calculated and compared between twice and thrice per week hemodialysis groups. Also compared adequacy variables between groups who achieved cutoff values of spKt/V, URR, TAC urea and nPCR with who did not achieve it. The ethical approval of the study was obtained from ethical review committee of Directorate General Medical Services (DGMS) Bangladesh armed forces. Data analysis was performed by Statistical Package for Social Science (SPSS), version-17. Statistical analyses were done and level of significance was measured by using appropriate procedures like student's t- test and others where applicable. Level of significance ( $p$ value) was set at 0.05 and confidence interval at $95 \%$. Results are presented as text and tables.

\section{Results:}

Total 137 patients were included in this study, among them $98(71.53 \%)$ were male and $39(28.46 \%)$ were female. Male female ratio was 2.5:1.

Forty-nine patients were in the age group of more than 60 years. The mean age of patient in this study was $53.37 \pm 13.43$ years. Only six patients were under 30 years of age.

One hundred patients $(72.99 \%)$ were on twice per week (8 hours/week) hemodialysis session and thirty-seven (27.01\%) were on thrice weekly (12 hours/week) hemodialysis session.
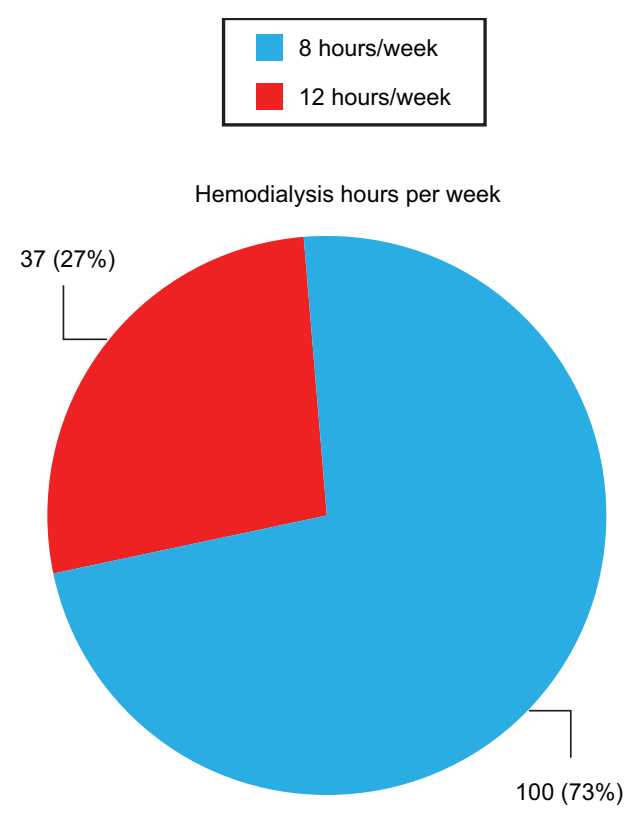

Fig.-1: Hemodialysis hours per week 
Table-I

Adequacy parameter of all hemodialysis patients $(n=137)$

\begin{tabular}{lc} 
Variables & Mean $\pm \mathrm{SD}$ \\
\hline Urea Reduction Ratio (URR) \% & $64.68 \pm 17.07$ \\
Single session spKt/V & $1.63 \pm 0.45$ \\
TAC urea (mg/dl) & $76.55 \pm 25.73$ \\
nPCR (gm/kg/day) & $1.43 \pm 0.55$ \\
\hline
\end{tabular}

Table II shows the hemodialysis adequacy parameters of different variables

Table-II

Comparison of sample mean value with target value $(n=137)$

\begin{tabular}{|c|c|c|c|}
\hline Adequacy & Parameters & Sample Mean \pm SD & Target Value \\
\hline $\operatorname{URR}(\%)(n=137)$ & $64.68 \pm 17.07$ & $>65$ & \\
\hline $\mathrm{SpKt} / \mathrm{V}(\mathrm{n}=137)$ & 8 hours/week $(n=100)$ & $1.80 \pm 0.35$ & $>2$ \\
\hline TACurea & 12 hours/week $(n=37)$ & $1.18 \pm 0.35$ & $>1.2$ \\
\hline \multirow[t]{2}{*}{ nPCR } & & $76.55 \pm 25.73$ & $<52$ \\
\hline & & $1.43 \pm 0.55$ & $>1$ \\
\hline
\end{tabular}

Mean URR of study population was lower than target value. In this study spKt/V of 8 hours per week hemodialysis group was lower than target value. Similarly in 12 hours per week hemodialysis group mean spKt/V value could not reach target value. Mean TACurea higher than target value $(<52 \mathrm{mg} / \mathrm{dl})$.

\section{Table-III}

Distribution of study population on the basis of cut off values of hemodialysis adequacy parameters $(n=137)$

\begin{tabular}{llcccc} 
Parameters & & Cut of Values & Mean \pm SD & & $\mathrm{n}$ \\
\hline URR $(\%)(\mathrm{N}=137)$ & & $>65$ & $81.52 \pm 9.89$ & 57 & 41.61 \\
& & $<65$ & $52.69 \pm 9.07$ & 80 & 58.39 \\
& & $>2$ & $2.40 \pm 0.25$ & 21 & 21.00 \\
$\mathrm{Kt} / \mathrm{V}$ & $(\mathrm{n}=100)$ & $<2$ & $1.64 \pm 0.14$ & 79 & 79.00 \\
$\mathrm{~N}=137$ & 12 hours/week & $>1.2$ & $1.53 \pm 0.25$ & 16 & 43.24 \\
& $(\mathrm{n}=37)$ & $<1.2$ & $0.92 \pm 0.08$ & 21 & 56.76 \\
\hline
\end{tabular}

Among the 100 patients in the group of 8 hours per week hemodialysis, only 21 (21\%) had Kt/V more than 2 and 79 (79\%) $\mathrm{had} \mathrm{Kt/V}$ less than 2. Among the 37 patients in the group of 12 hours per week hemodialysis, 16 (43.24\%) had spKt/V more than 1.2 and $21(56.76 \%)$ had spKt/V less than 1.2. Among 137 patients only $57(41.61 \%)$ achieved URR $>65 \%$.

Table-IV

\begin{tabular}{lccc}
\multicolumn{2}{c}{ Comparisons on the basis of spKt/V cut off values of 8 hours/ week hemodialysis group $(n=100)$} \\
Variables & \multicolumn{2}{c}{ Mean $\pm \mathrm{SD}$} & $\mathrm{p}$-value \\
\cline { 2 - 4 } & $\mathrm{spKt} / \mathrm{V}>2(\mathrm{n}=21)$ & $57.01 \pm 11.68$ & $<0.001$ \\
\hline URR & $53.82 \pm 05.30$ & $81.83 \pm 23.99$ & $<0.001$ \\
TACurea & $01.83 \pm 0.71$ & $1.48 \pm 0.51$ & 0.012 \\
nPCR &
\end{tabular}

In 8 hours/week group those who achieve target spKt/V also achieve target URR and was statistically significant. And there is significant difference among the two group $(\operatorname{spKt} / \mathrm{V}>2 \mathrm{Vs} \operatorname{spk} / \mathrm{V}<2)$ in relation to TACurea and $\mathrm{nPCR}(\mathrm{p}<.05)$. 
Table-V

Comparisons on the basis of spKt/V cut off values of 12 hours /week haemodialysis group ( $n=37$ ).

\begin{tabular}{lccc} 
Variables & \multicolumn{2}{c}{ Mean $\pm \mathrm{SD}$} & $\mathrm{p}$-value \\
\cline { 2 - 4 } & $\mathrm{spKt} / \mathrm{V}>1.2(\mathrm{n}=16)$ & $\mathrm{spKt} / \mathrm{V}<1.2(\mathrm{n}=21)$ & $<0.001$ \\
\hline URR & $84.29 \pm 6.62$ & $53.41 \pm 6.97$ & 0.006 \\
TAC urea & $65.16 \pm 16.01$ & $88.12 \pm 27.94$ & $<0.001$ \\
nPCR & $1.34 \pm 0.35$ & $0.94 \pm 0.18$ & \\
\hline
\end{tabular}

URR, TAC urea and nPCR was significantly better in patients with $\mathrm{spKt} / \mathrm{V}>1.2$ group.

Table-VI

Comparisons on the basis of URR cut off values $(n=137)$

\begin{tabular}{lccc}
\multirow{2}{*}{ Variables } & \multicolumn{2}{c}{ Mean \pm SD } & p-value \\
\cline { 2 - 3 } & $\mathrm{URR}(\%)>65(\mathrm{n}=57)$ & $\mathrm{URR}(\%)<65(\mathrm{n}=80)$ & \\
\hline SpKt $/ \mathrm{V}$ & $1.95 \pm 0.42$ & $1.41 \pm 0.31$ & $<0.001$ \\
TAC urea & $64.88 \pm 21.82$ & $84.87 \pm 25.18$ & 0.006 \\
nPCR & $1.65 \pm 0.60$ & $1.28 \pm 0.46$ & $<0.001$ \\
\hline
\end{tabular}

TAC urea, $\mathrm{nPCR}$ and spKt/V, significantly better in URR more than $65 \%$ groups.

Blood flow of study population:

Table-VII

Distribution of blood flow per minute of the study population $(n=137)$

\begin{tabular}{lcc} 
Blood flow/minute & Frequency & Percentage \\
\hline$<250 \mathrm{ml}$ & 85 & 62.04 \\
$\geq 250 \mathrm{ml}$ & 52 & 37.96 \\
Total & 137 & 100 \\
\hline
\end{tabular}

Eighty-five (62.04\%) of the study population underwent hemodialysis with blood flow rate under $250 \mathrm{ml} / \mathrm{min}$. Remaining 52 (37.96\%) patient's blood flow rate were above $250 \mathrm{ml} / \mathrm{min}$.

\section{Adequacy on the basis blood flow:}

Table-VIII

Adequacy on the basis blood flow of the study population $(n=137)$

\begin{tabular}{lccc} 
& \multicolumn{2}{c}{ Mean \pm SD } & p-value \\
\cline { 2 - 3 } & $<250 \mathrm{ml}(\mathrm{n}=85)$ & $\geq 250 \mathrm{ml}(\mathrm{n}=52)$ & \\
\hline (URR) \% & $54.51 \pm 11.52$ & $81.31 \pm 10.21$ & $<0.001$ \\
SpKt $/ \mathrm{V}$ & $1.41 \pm 0.31$ & $1.99 \pm 0.41$ & $<0.001$ \\
TAC urea & $83.68 \pm 25.68$ & $64.91 \pm 21.37$ & $<0.001$ \\
nPCR & $1.27 \pm 0.47$ & $1.70 \pm 0.57$ & $<0.001$ \\
\hline
\end{tabular}

Patients who do there dialysis with blood flow more than $250 \mathrm{ml} / \mathrm{min}$ had significantly better dialysis adequacy. $\operatorname{URR}(81.31 \pm 10.21$ vs. $54.51 \pm 11.52$ and $p$-value $<0.001)$, spKt/V $(1.99 \pm 0.41$ vs. $1.41 \pm 0.31$ p-value $<0.001)$.

\section{Discussion:}

The present study was conducted to observe optimum solute clearance per session of hemodialysis by applying spKt/V and URR formula. In this study mean age of patients were Mean $\pm \operatorname{SD}(53.37 \pm 13.43)$ years (Table-1). Similarly Sultania et al of Nepal in their study showed that the mean age of the patients was $49 \pm 24$ years $^{12}$. One hundred $(72.99 \%)$ patients were on 2 sessions ( 8 hours) per week hemodialysis group (Fig. I). Anees et al in their study showed that 1,2 and 3 sessions per week hemodialysis were 7.2\%, 77.6\% and 15.2\% respectively ${ }^{13}$. 'Twice-weekly HD is prevalent in the developing countries' ${ }^{14}$. We also found majority of the patients were in 8 hours /week hemodialysis group. Thrice-weekly HD is regarded as a standard renal replacement therapy (RRT) for maintenance dialysis, and the KDOQI guidelines, 2006 indicates that twice-weekly hemodialysis is not appropriate for patients who have residual renal function $<2 \mathrm{ml} / \mathrm{min} / 1.73 \mathrm{~m} 2{ }^{15}$. In this study mean spKt/V of all study population was $1.63 \pm 0.45$ (Table II). In 8 hours per week hemodialysis group, out of 100 patients, $21(21 \%)$ patients achieved target spKt/ $\mathrm{V}>2$. On the other hand in 12 hours per week hemodialysis group, out of 37 patients, 16 (43.24\%) achieved target spKt/V $>1.2$ (table IV). Karin et al similarly showed that; mean spKt/V was $1.18 \pm 0.26$ for 12 hours/week group and $1.90 \pm 0.35$ for 8 hours/week 
group of his study population ${ }^{16}$. Manouchehr et al in their National Multicenter Study in Iran among 4004 study population showed that spKt/V was less than 1.2 in $56.7 \%$, of the patients ${ }^{17}$. In this study also most of the patients could not achieve target value. Mean URR of all study population was $64.68 \pm 17.07$ (table II) and only $57(41.61 \%)$ patient could achieved the cutoff value of adequacy and $80(58.39 \%)$ patients had URR $<65 \%$ (table IV). Similar study done by Lin et al of Taiwan studied over 74 patients ( 23 twice weekly and 51 thrice weekly dialyzed patients) and shown no significant difference $(77.77 \pm 5.44 \text { vs. } 75.47 \pm 6.27 \mathrm{p} \text {-value } 0.114)^{18}$. We also did not get any significant difference in URR (p-value 0.338 ) between 8 hours/week and 12 hours/ week group. In 8 hours/week group those who achieve target spKt/V also achieved target URR and was statistically significant. TAC urea was significantly close to the target in spKt/V $>2$ group and nPCR also better maintained in patients with spKt/V $>2$. TAC urea, $n P C R$ and $\mathrm{spKt} / \mathrm{V}$, significantly better in URR more than $65 \%$ groups. (Table V, VI, VII) This study showed that only $52(37.95 \%)$ patients had blood flow rate (BFR) $\geq 250 \mathrm{ml} /$ min during dialysis and their average URR was $81.31 \pm$ 10.21, which is significantly higher than the URR of blood flow rate less than $250 \mathrm{ml} / \mathrm{min}$ group (p-value $<0.001)$. Similarly other indices of adequacy of dialysis such as spKt/V shows significantly better value $1.99 \pm$ 0.41 in BFR e" $250 \mathrm{ml} / \mathrm{min}$ group (p-value $<0.001$ ). The DOPPS has shown that BFR is more than $400 \mathrm{ml} / \mathrm{min}$ account for $83.6 \%$ of the HD patients in United States 19. In Canada and Europe, the patients with BFR $>250$ $\mathrm{ml} / \mathrm{min}$ take about $98 \%$ of the HD patients. Comparing our data with similar studies it was clear that quality of dialysis in this center was not adequate. But by increasing the BFR it could be improved. Although dialysis facilities in Japan are concerned about the increased load on the cardiovascular system with increasing blood flow, acute changes in cardiac function was not observed in blood flow between 400 and 500 $\mathrm{ml} / \mathrm{min}^{20}$.

\section{Conclusion:}

We found that most of our hemodialysis patients were inadequately dialyzed which were most likely contributed by decrease dialysis frequency and low blood flow. So to achieve hemodialysis adequacy it needs to increase the frequency of dialysis from two to three sessions per week and measure should be taken to ensure the adequate blood flow (more than $250 \mathrm{ml} / \mathrm{min}$ ) during dialysis.

\section{Reference:}

1. Singh AK, Farag YM, Mittal BV, Subramanian KK, Reddy $\mathrm{SR}$, Acharya VN, et al. 'Epidemiology and risk factors of chronic kidney disease in India - Results from the SEEK (screening and early evaluation of kidney disease) study'. BMC Nephrol, 2013; 14: 114.

2. Kepler J, Annual Data Report: Atlas of Chronic Kidney Disease and End-Stage Renal Disease in the United States. 2010; Vol. 2.

3. Coresh J, Selvin E, Stevens L.A, Manzi J, Kuse J W, Eggers $\mathrm{P}$, et al. Prevalence of chronic kidney disease in the United States. JAMA. 2007; 298: 2038-47

4. Casula A, Webb L, Feest T, Adequacy of hemodialysis in UK adult patients in 2009: National and centre-specific analyses. UK Renal Registry 13th Annual Report 2011; 119 141-7.

5. USRDS (US Renal Data System ), Annual Data Report: Atlas of End-Stage Renal Disease in the United States, Bethesda, National Institutes of Health, National Institute of Diabetes and Digestive and Kidney Diseases; 2016:23

6. Rao M, Juneja R, Shirly RB, Jacob CK. Haemodialysis for end-stage renal disease in Southern India - A perspective from a tertiary referral care centre. Nephrol Dial Transplant. 2016; 13: 2494-500.

7. Debowska M, Waniewski J, Lindholm B. 'Adequacy indices for dialysis in acute renal failure: kinetic modeling'. Artificial Organs. 2010; 4 (5):412-419.

8. NKF-K/DOQI, 2006, Clinical Practice Guidelines for Haemodialysis Adequacy update: Am J Kidney Dis. 2015; 37: 7-64.

9. Depner T A. 'Haemodialysis adequacy: basic essentials and practical points for the nephrologist in training', Hemodial Int. 2005; vol. 9(3):241-54.

10. Locatelli F, Buoncristiani U, Canaud B, Kohle, H, Petitclerc, T, Zucchelli P. et al. 'Dialysis dose and frequency'. Nephrol Dial Transplant. 2005 ; 20(2):285-96.

11. Chowdhury NS, Islam FMM, Zafreen F, Begum BA, Sultana $\mathrm{N}$, Perveen S, et al. 'Effect of surface area of dialyzer membrane on the adequacy of hemodialysis'. 2011. JAFMC Bangladesh; 7(2):9-11.

12. Sultania P, Acharya PS, Sharma SK, 'Adequacy of hemodialysis in Nepalese patients undergoing maintenance hemodialysis'. J Nepal Med Assoc. 2009 ; 48(173):10-3.

13. Anees M, Hamee, F, Mumtaz A, Ibrahim M, Khan M N S 'Dialysis related factors affecting quality of life in patients on hemodialysis' IJKD. 2011; 5:9-14. 
14. Lin X., Yan Y, Ni Z, Gu L, Zhu M, Dai H, et al. 'Clinical Outcome of Twice-Weekly Haemodialysis Patients in Shanghai'. Blood Purif. $2012 ; 33: 66-72$.

15. NKF-K/DOQI, 2006, Clinical Practice Guidelines for Haemodialysis Adequacy update: 2006. Am J Kidney Dis. 2006; 37:7-64.

16. Karin E, Moret DC, Grootendorst FW, Dekker EW, Boeschoten RT, Krediet S. et al. 'Agreement between different parameters of dialysis dose in achieving treatment targets: results from the NECOSAD study', Nephrol Dial Transplant. 2012 ;vol. 27( 3):1145-1152

17. Manouchehr A, Mohammad A, Farzad M, kabir M, Zamyadi S, Norouzi H R, et al. 'Haemodialysis Adequacy and Treatment in Iranian Patients A National Multicenter Study'. Iranian Journal of Kidney Diseases. 2011 ; 5:103-109

18. Lin X, Yan Y, Ni Z, Gu L, Zhu M, Dai H, et al. 'Clinical Outcome of Twice-Weekly Haemodialysis Patients in Shanghai'. Blood Purif. 2012; 33:66-72.

19. Eric W. Y, David A G, Donna L M, Friedrich K P, Marcia L K, Kenneth C, Bradley L M, Robert A W, Philip J. The Dialysis Outcomes and Practice Patterns Study (DOPPS): An international hemodialysis study ;Kidney International, 2000; Vol. 57, Suppl. 74:74-81

20. Watanabe Y, Kawanishi H ,Suzuki K, Nakai S, Tsuchida K,Tabei K, et al. "Japanese Society for Dialysis Therapy Clinical Guideline for "Maintenance Haemodialysis: Haemodialysis Prescriptions', Therapeutic Apheresis and Dialysis, 2015 ; 19(1):67-92 